\section{Proproteinkonvertase Subtilisin/Kexin Typ 9}

\author{
K. J. Lackner ${ }^{1}$ und D. Peetz ${ }^{2}$ \\ ${ }^{1}$ Institut für Klinische Chemie und Laboratoriumsmedizin, \\ Universitätsmedizin Mainz, Mainz, Deutschland \\ ${ }^{2}$ Institut für Labormedizin, Helios Klinikum Berlin-Buch, \\ Berlin, Deutschland
}

Synonym(e) PCSK9; Neurale Apoptose-regulierte Konvertase 1 ; NARC1

Englischer Begriff proprotein convertase subtilisin/kexin type 9

Definition Serinprotease, die an den Komplex aus LDLRezeptor und LDL bindet.

Beschreibung PCSK9 wird als 692 Aminosäuren langes Proprotein in verschiedenen Organen, hauptsächlich Leber, Dünndarm und Niere, synthetisiert. Ein 30 Aminosäuren langes Signalpeptid wird kotranslational abgespalten. Das Enzym wird autokatalytisch durch Abspaltung eines ca. $14 \mathrm{kDa}$ großen aminoterminalen Propeptids aktiviert. Missense-Mutationen in PCSK9 wurden zunächst als Ursache von Fällen autosomal dominanter Hypercholesterinämie beschrieben. Später zeigte sich, dass Nonsense-Mutationen in PCSK9 (Y142X und C679X), die vor allem bei Personen schwarzafrikanischer Herkunft gefunden wurden, mit einem deutlich verminderten LDL-Cholesterin einhergehen. Heterozygote Mutationsträger haben ein stark vermindertes Arterio- skleroserisiko. In PCSK9 gibt es also Mutationen mit einer gesteigerten Funktion, die zur Hypercholesterinämie führen, und Mutationen mit einem Funktionsverlust, die zu niedrigen Cholesterinkonzentrationen im Serum führen. Die Effekte auf den LDL-Stoffwechsel sind unabhängig von der enzymatischen Funktion von PCSK9. Es wurde gezeigt, dass PCSK9 an den Komplex aus LDL und $>$ LDL-Rezeptor an der Zelloberfläche bindet, mit dem Komplex internalisiert wird und im Endosom verhindert, dass Rezeptor und Ligand dissoziieren. Als Folge werden LDL-Rezeptormoleküle in Gegenwart von PCSK9 verstärkt lysosomal degradiert und können nicht mehr an die Zelloberfläche zurückkehren. Dies führt zu einer verminderten Expression des LDL-Rezeptors auf der Zelloberfläche und einer verminderten Aufnahme von LDLPartikeln. Inzwischen wurden PCSK9-Inhibitoren entwickelt und zugelassen (Evolocumab, Alirocumab). In Phase-IIIStudien konnte gezeigt werden, dass PCSK9-Inhibition mittels spezifischer Antikörper oder siRNA zu einer massiven Senkung des LDL-Cholesterins führt. PCSK9 kann im Serum mittels Immunoassay bestimmt werden. Die Analyse ist aber nur im Rahmen klinischer Studien von Bedeutung.

\section{Literatur}

Cohen JC, Boerwinkle E, Mosley TH Jr et al (2006) Sequence variations in PCSK9, low LDL, and protection against coronary heart disease. N Engl J Med 354:1264-1272

Navarese EP, Kolodziejczak M, Dimitroulis D et al (2016) From proprotein convertase subtilisin/kexin type 9 to its inhibiton: state-ofthe-art and clinical implications. Eur Heart J Cardiovasc Pharmacother 2:44-53 